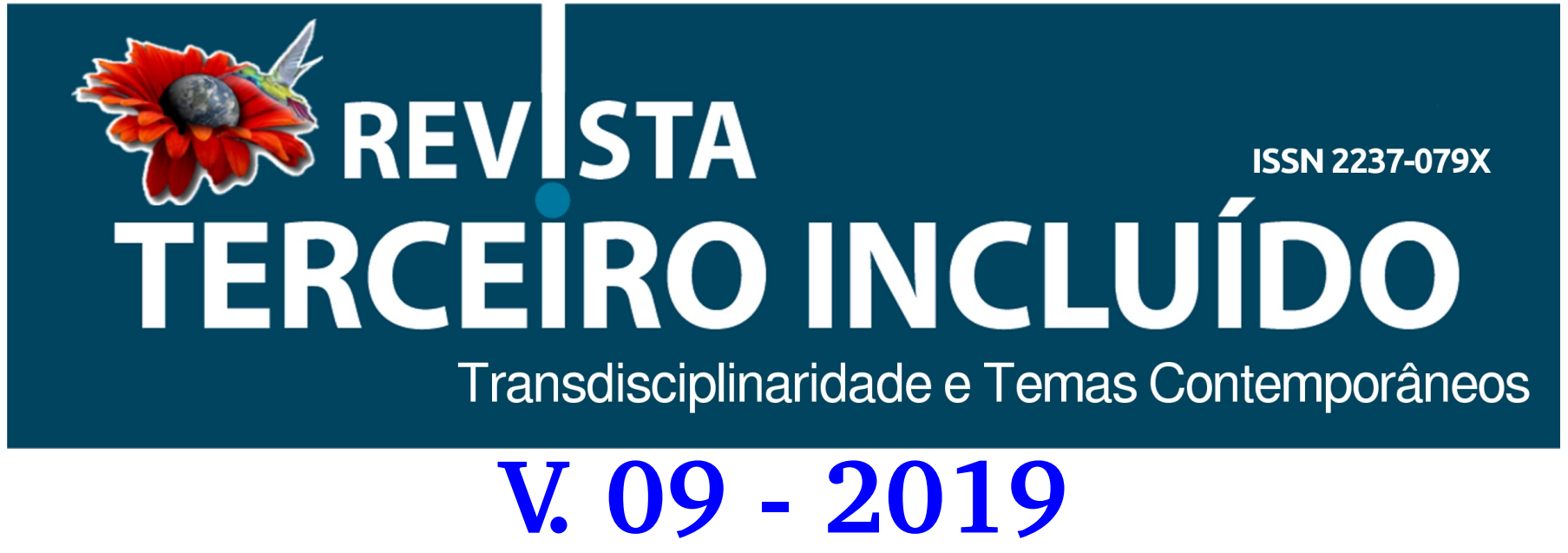

JUNGER, Alex Paubel; MEDEIROS, Andressa Rodrigues de; MOURA, Débora Martins Viana de; BARROCAL, Rebeca Rosa; AMARAL, Luiz Henrique.

Marketing Infantil: A Influência Midiática No Desenvolvimento Psicológico De Crianças E Adolescentes

pp. 93-103

DOI: $10.5216 /$ teri.v9i1.56012 


\title{
MARKETING INFANTIL: A INFLUÊNCIA MIDIÁTICA NO DESENVOLVIMENTO PSICOLOGICCO DE CRIANÇAS E ADOLESCENTES
}

\author{
CHILD MARKETING: THE MIDI INFLUENCE IN THE \\ PSYCHOLOGICAL DEVELOPMENT OF CHILDREN AND \\ ADOLESCENTS
}

\section{MARKETING INFANTIL: LA INFLUENCIA MIDIÁTICA EN EL DESARROLLO PSICOLOGICO DE NINOS Y ADOLESCENTES}

\author{
Alex Paubel Junger ${ }^{1}$ \\ Andressa Rodrigues de Medeiros ${ }^{2}$ \\ Débora Martins Viana de Moura ${ }^{3}$ \\ Rebeca Rosa Barrocal ${ }^{4}$ \\ Luiz Henrique Amaral ${ }^{5}$
}

Resumo: Este artigo tem como objetivo apresentar como o marketing infantil influencia o desenvolvimento de crianças e adolescentes, explicitando quais meios midiáticos possui maior impacto, por meio dos conceitos de estratégias de diferenciação e segmentação comportamental. Tem-se como objetivo também, mostrar a percepção das crianças, adolescentes e pais em relação à exposição que estes são submetidos diariamente de forma massiva. A intenção é estudar o poder do marketing infantil no desenvolvimento do seu público-alvo e como isso reflete no poder de compra dos pais, visando explanar o modo como a publicidade mercadológica está voltada para as crianças $e$ as influências que essa prática exerce sobre o desenvolvimento físico, psicológico e social desses que serão consumidores ativos no futuro. Devido a grande influência do marketing infantil na vida de crianças e adolescentes se faz necessário seu estudo e pesquisa, sendo que conexão que é feita entre o real e o imaginário povoa as mentes em formação. A mídia e a publicidade infantil são responsáveis por inflar essas mentes, com a intenção de ampliar o consumo de determinados produtos, especialmente aqueles voltados para o público infantil.

Palavras-chave: educação, publicidade, influência, consumo.

Abstract: This article aims to present how child marketing influences the development of children and adolescents, explaining which media has the greatest impact, through the concepts of strategies of differentiation and behavioral segmentation. The objective is also to show the perception of children, adolescents and parents in relation to the exposure that they are submitted daily in a massive way. The intention is to study the power of children's marketing in the development of their target audience and how this reflects on the purchasing power of parents in order to explain how marketing advertising is directed at children and the influences that this practice has on development physical, psychological and social development of those who will be active consumers in the future. Due to the great influence of child marketing on the life of children and adolescents, it is necessary to study and research, and the connection between the real and the imaginary populates the minds in formation. The media and children's advertising are responsible for inflating these minds, with the intention of increasing the consumption of certain products, especially those aimed at the children's audience.

Key words: education, advertising, influence, consumption.

Resumen: Este artículo tiene como objetivo presentar cómo el marketing infantil influye en el desarrollo de niños y adolescentes, explicitando qué medios mediáticos tienen mayor impacto, a través de los conceptos de estrategias de diferenciación y segmentación conductual. Se tiene como objetivo también, mostrar la percepción de los niños, adolescentes y padres en relación a la exposición que estos son sometidos diariamente de forma masiva. La intención es estudiar el poder del marketing infantil en el desarrollo de su público objetivo y cómo esto refleja en el poder adquisitivo de los padres, con el fin de explicar cómo la publicidad mercadológica está orientada hacia los niños y las influencias que esta práctica ejerce sobre el desarrollo físico, psicológico y social de los que serán consumidores activos en el futuro. Debido a la gran influencia del marketing infantil en la vida de niños y adolescentes se hace necesario su estudio e investigación, siendo que la conexión que se hace entre lo real y lo imaginario puebla las mentes en formación. Los medios y la publicidad infantil son responsables de inflar esas mentes, con la intención de ampliar el consumo de determinados productos, especialmente aquellos dirigidos al público infantil.

Palabras clave: educación, publicidad, influencia, consumo.

\footnotetext{
1 Pós-Doutor em Engenharia e Gestão da Inovação e Professor do Programa de Pós-Graduação da Faculdade de Tecnologia Termomecânica (São Bernardo do Campo/SP).

2 Estudante de Administração da Faculdade de Tecnologia da Termomecânica (São Bernardo do Campo/SP).

3 Estudante de Administração da Faculdade de Tecnologia da Termomecânica (São Bernardo do Campo/SP).

4 Estudante de Administração da Faculdade de Tecnologia da Termomecânica (São Bernardo do Campo/SP).

5 Professor do Programa de Pós-Graduação em Ensino da Universidade Cruzeiro do Sul (São Paulo/SP).
} 
O consumo faz parte do cotidiano do ser humano. Homens, mulheres, crianças e jovens são os responsáveis por fazerem o mercado financeiro se movimentar o tempo todo. A era do capitalismo influencia as empresas para que vendam mais seus produtos e, para isto, são utilizados diversos canais de comunicação para atingir os públicos alvos. Esses canais de comunicação causam impactos significativos na sociedade, sendo eles positivos e negativos. Uma das maiores utilizações desses canais está presente no marketing infantil. Uma pesquisa feita pelo Serviço de Proteção ao Crédito brasileiro em 2015 (SPC) afirmou que 64\% dos pais adquirem produtos não necessários solicitados pelos filhos, como um brinquedo, uma roupa nova, doces, entre outros. Produtos licenciados são os produtos que mais influenciam as crianças na hora da compra, principalmente aqueles relacionados a personagens. Com o intuito de identificar a partir da percepção das mães e o grau de influência que determinados produtos exercem sobre as crianças, a pesquisa investigou 10 estímulos diferentes aos quais os (as) filhos(as) são continuamente expostos (as). A grande gama de propagandas espalhadas em anúncio e, principalmente, pela televisão, acaba ocasionando uma pressão contínua sobre pais e responsáveis e influenciando a formação e desenvolvimento das crianças. A questão que permeia os pais e responsáveis é de como agir para que as crianças aceitem a enfrentar as limitações que as atingirão no decorrer da vida. É necessário, então, preparar a criança desde idade tenra, para saber agir e interagir com as informações recebidas pelo mundo exterior, para que ela se torne um consumidor do futuro consciente, saber como e por que comprar, ciente de suas reais necessidades e consciente de suas responsabilidades. Buscamos identificar como os atores na educação infantil podem desempenhar ações que promovam educação para o embate diante da indústria publicitária sobre as crianças.

Os itens licenciados são os maiores influenciadores na hora da compra, como pode-se observar na tabela 1:

Tabela 1: Influência dos itens licenciados no momento de compra

\begin{tabular}{|c|c|c|c|c|c|c|c|c|}
\hline \multirow{2}{*}{ RU } & \multirow{2}{*}{ GERAL } & \multicolumn{2}{|c|}{$\begin{array}{l}\text { SEXO DO(A) } \\
\text { FILHO(A) }\end{array}$} & \multicolumn{3}{|c|}{ IDADE DO(A) FILHO(A) } & \multicolumn{2}{|c|}{ CLASSE } \\
\hline & & MASC. & FEM. & $\begin{array}{l}2 \text { A5 } \\
\text { ANOS }\end{array}$ & $\begin{array}{l}\text { 6A11 } \\
\text { ANOS }\end{array}$ & $\begin{array}{l}12 \text { A } 18 \\
\text { ANOS }\end{array}$ & $A / B$ & C/D/E \\
\hline $\begin{array}{l}\text { Personagens licenciados } \\
\text { - brinquedos }\end{array}$ & 5,79 & 5,81 & 5,78 & 7,19 & 6,15 & 4,76 & 5,87 & 5,68 \\
\hline $\begin{array}{l}\text { Personagens licenciados } \\
\text { - material escolar }\end{array}$ & 5,71 & 5,55 & 5,88 & 6,71 & 5,78 & 5,14 & 5,75 & 5,66 \\
\hline $\begin{array}{l}\text { Produtos licenciados - } \\
\text { roupas e calçados }\end{array}$ & 5,70 & 5,62 & 5,78 & 6,86 & 5,64 & 5,14 & 5,68 & 5,72 \\
\hline Propagandas na TV & 5,58 & 5,75 & 5,4 & 5,36 & 5,88 & 5,44 & 5,7 & 5,41 \\
\hline Amigos e Familia & 5,27 & 5,2 & 5,35 & 4,45 & 5,37 & 5,62 & 5,37 & 5,14 \\
\hline Produtos no PDV & 4,91 & 5,19 & 4,61 & 5,25 & 5,08 & 4,58 & 4,97 & 4,82 \\
\hline $\begin{array}{l}\text { Propagandas na } \\
\text { Internet }\end{array}$ & 4,87 & 4,97 & 4,77 & 3,56 & 4,94 & 5,49 & 4,95 & 4,75 \\
\hline Brindes Colecionáveis & 4,86 & 5,27 & 4,45 & 4,61 & 5,26 & 4,65 & 5,05 & 4,61 \\
\hline Marcas Famosas & 4,58 & 4,89 & 4,26 & 3,59 & 4,43 & 5,22 & 4,65 & 4,49 \\
\hline Embalagens atrativas & 4,56 & 4,63 & 4,49 & 4,70 & 5,04 & 4,07 & 4,81 & 4,21 \\
\hline
\end{tabular}

Fonte: SPC. Consumo Infantil. Disponível em: <htpps://www.spcbrasil.org.br/uploads/st_imprensa/analise_consumo_infantil_setembro_20151.pdf> Acesso em: 11 de nov. de 2018. 
Dessa maneira, é possível notar o quanto as propagandas vinculadas a produtos licenciados influenciam grandemente na hora das exigências de decisão de compra do público infantil, fato que, certamente, interfere nos hábitos de consumo do público em questão, o que reforça e endossa a relevância dessa pesquisa.

\section{FUNDAMENTAÇÃO TEÓRICA}

Tendo em vista o rigor acadêmico inerente a academia e a pesquisa, se apresenta nesse momento o contexto teórico no qual se sustenta esse constructo, portanto, serão expostos os pressupostos teóricos e filosóficos que contribuem para atingir e responder acerca da problemática proposta a priori, bem como atingir os objetivos apontados.

\subsection{A CONSTRUÇÃO DO CARÁTER DO INDIVÍDUO}

Segundo Reich (1989, p. 151), o caráter consiste numa mudança crônica do ego que se poderia descrever como um enrijecimento. Segundo a psicologia, este caráter é formado ainda na primeira infância, através da interação entre a criança e o meio, que consiste desde o nascimento até os seis anos de idade, onde as descobertas, experiências e afetos são levados para o resto da vida.

De acordo com Sócrates (apud Salis, 2002, p. 18), “temos pouco tempo para a virtude e toda a vida para o conhecimento, pois o vício e a mentira logo se instalam no caráter do jovem, sendo tarefa quase sempre fadada ao fracasso tentar extirpá-los mais tarde". Ao vício e a mentira citados por Sócrates, podemos adicionar mais um mal deste século: o consumismo.

Assim sendo influência do marketing infantil na vida de crianças e adolescentes necessita ser estudada, pois a mistura feita entre o real e o imaginário rodeia as mentes em formação. A mídia e a publicidade infantil são responsáveis por bombardear essas mentes, com a intenção de ampliar o consumo de determinados produtos, especialmente aqueles voltados para o público infantil.

A grande gama de propagandas espalhadas em anúncios e, principalmente, pela televisão, acaba ocasionando uma pressão contínua sobre pais e responsáveis, influenciando a formação e desenvolvimento das crianças. A questão que passa a envolver os pais e responsáveis é como agir para que essas crianças aprendam a lidar com as limitações que enfrentarão no decorrer da vida. É necessário, então, preparar a criança desde pequena, para saber lidar com essas informações recebidas pelo mundo exterior, para que ela se torne um consumidor do futuro consciente, saber como e por que comprar, entendendo suas reais necessidades e responsabilidades.

Nesse sentido as crianças de hoje, são o futuro da humanidade e a responsabilidade de orientar essas crianças da melhor forma possível não é dever somente dos pais, mas também da sociedade como um todo, pois a criança recebe influência do meio externo em todo momento.

Jean Piaget (1896 a 1980) contribuiu com estudos de como nasce e se desenvolve o conhecimento e a evolução desse conhecimento humano até a adolescência, sua intenção era entender como o desenvolvimento das estruturas cognitivas do homem e os mecanismos mentais que o indivíduo utiliza para captar o mundo.

Segundo Piaget (1975, p.351), durante os primeiros anos de existência, a criança não 
dissocia o mundo exterior da sua atividade própria, pois os quadros perceptivos ainda não se consolidaram em objetos e nem estão coordenados em um espaço coerente, mas, são comandados pelos seus desejos e esforços, sem que estes, por outro lado, sejam atribuídos a um eu distinto desse universo.

Os períodos do desenvolvimento são caracterizados por aquilo que o indivíduo faz de melhor em sua faixa etária: sensório-motor, pré-operatório, operações concretas e as operações finais. Todos os indivíduos passam por essas etapas no decorrer da sua vida, porém o início e o término de cada período varia de acordo com as característica biológicas do ser humano, além dos fatores educacionais e sociais.

No período sensório-motor, caracterizado de zero aos dois anos, a forma que os bebês conhecem ao mundo são sensório-motoras, ou seja, predomina-se as percepções sensoriais e dos movimentos.

No período pré-operatório, caracterizado dos dois aos sete anos, a criança desenvolve a lógica, com a descoberta do símbolo e a aprendizagem da fala. Nesta fase a inteligência é caracterizada em intuitiva, pois não se separa da experiência vivida, ou seja, a criança não transpõe abstratamente o que foi vivenciado pela percepção. A inteligência se torna egocêntrica.

No período das operações concretas, caracterizado dos sete aos doze anos, a criança representa grande evolução da ação às operações mentais concretas, elas se tornam concretas porque se baseiam em objetos e não em apenas hipóteses, uma habilidade que será concreta na última fase.

No período das operações finais, caracterizado por ocorrer dos onze aos doze anos em diante, ocorre o amadurecimento das características da vida adulta. Para Piaget, as mudanças na forma como adolescentes raciocinam sobre si, sobre seus relacionamentos pessoais e sobre o caráter da sua sociedade, têm como fonte comum o desenvolvimento de uma nova estrutura lógica que ele declarava como operações finais.

O mundo atual está rodeado pela grande influência do Marketing, seja ela formal ou informal. Segundo Kotler (2013), um bom Marketing não é acidental, mas um resultado de um cuidadoso processo de planejamento e execução, que utiliza das mais variadas e avançadas técnicas e ferramentas disponíveis, pode ser considerado ao mesmo tempo como "arte" e "ciência", em que os profissionais da área se esforçam para encontrar novas soluções criativas, face aos complexos desafios que acontecem em meios as profundas mudanças de Marketing do século XXI.

O marketing é responsável por estudar e entender a identificação e satisfação das necessidades humanas e sociais. Uma das suas principais ações é transformar uma necessidade que é particular ou social em uma oportunidade lucrativa de negócio. A administração está envolvida no Marketing quando seleciona mercados-alvos, capta e fideliza clientes através da criação, entrega e comunicação de um valor superior ao cliente. Peter Drucker, um dos principais teóricos da administração, afirma que a venda é apenas uma consequência do Marketing, seu principal objetivo é tornar supérfluo o esforço da venda. o ponto está em conhecer também seu público-alvo que o produto ou serviço possa se adequar a ele e se vender sozinho.

Nesse contexto, se apresenta, por meio da figura 1, um sistema simples de Marketing para prover e facilitar compreensão a luz do referencial teórico supracitado. 
Figura 1: Sistema simples de Marketing

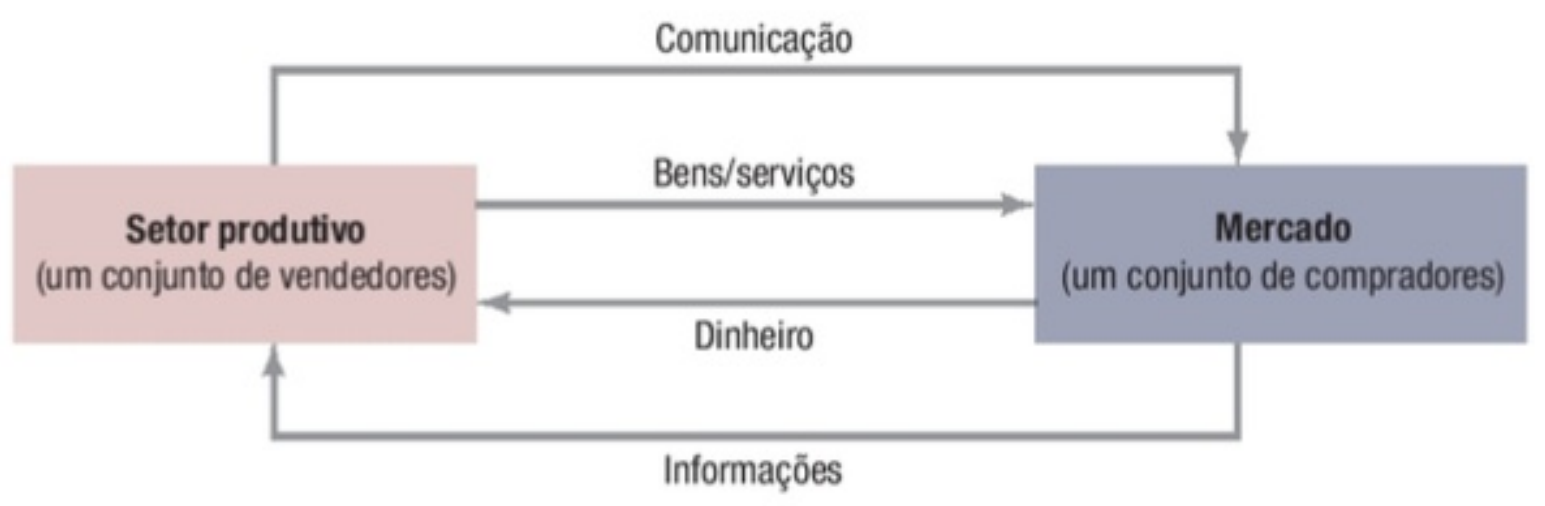

Fonte:Kotler (2013)

Se faz notório o fato de que o setor produtivo é a razão de perpetuidade de uma empresa, dessa forma, o mesmo tem a função de ofertar bens e serviços por meio de seus produtos (bens e serviços). Para tanto, as organizações se utilizarão de comunicação, visto que, é preciso demonstrar aos clientes qual é o valor agregado que o público-alvo deve perceber no ato da decisão de compra. Ao se atender a esse mercado, a lucratividade se fará evidente e usa de informações para retroalimentar esse processo, fato que, em princípio, permite que as empresas mobilizem suas estratégias e se tornam competitivas no mercado, com base no exposto, cabe uma discussão sobre os tipos de mercado que o marketing é capaz de absorver.

\subsection{TIPOS DE MERCADOS DE MARKETING}

Os principais mercados que o Marketing abrange são:

- Mercado Consumidor: São as empresas que comercializam produtos de consumo em massa. Elas investem na imagem da marca, para torná-la superior, através de embalagens adequadas, disponíveis nos locais adequados, sustentada por propagandas que envolvem e um serviço confiável.

- Mercado Organizacional: São as empresas que vendem bens ou serviços para outras empresas. As empresas que vendem esse tipo de produto devem demonstrar como eles ajudarão seus clientes a atingir receitas maiores e custos menores.

- Mercado Global: São as empresas que vendem seus bens ou serviços no mercado global. Suas preocupações estão em quais países valem a pena investir, de que forma entrar em cada um deles (como licenciado, exportador, parceiro, joint-venture, etc); como adaptar seus produtos e a sua comunicação a cultura de cada país, como determinar seus preços no mercado externo e como lidar como as flutuações da moeda e mudanças políticas.

- Mercados sem fins lucrativos ou governamentais: São as empresas que vendem seus produtos
ou serviço para instituições sem fins lucrativos e com um limitado poder de compra, como
igrejas, universidades, instituições de caridade e órgãos públicos. Suas preocupações estão em
determinar os preços com cautela, se atentar a qualidade dos produtos e serviços e atuar em
ofertar ações práticas.

Como todo ato de pesquisa, se faz necessário compreender o percurso metodológico que permite atingir o objetivo por hora proposto, no caso desse artigo, não é diferente, a saber conforme sequência: 


\section{METODOLOGIA}

Um método em sentido geral, é a ordem que se deve impor aos diferentes processos necessários para atingir um certo resultado desejado. A pesquisa é uma atividade voltada para investigação de problemas teóricos ou práticos por meio do emprego de processos científicos. Ela parte de uma dúvida ou um problema, e com o uso do método científico, busca uma resposta ou uma solução.

Em sua natureza, esse artigo tem como caráter a pesquisa bibliográfica baseada nos conceitos de Jean Piaget sobre a teoria do desenvolvimento cognitivo e o caráter descritivo. A pesquisa bibliográfica procura explicar um problema a partir de referência teóricas publicadas em artigos, livros, dissertações e teses. Pode ser realizada independentemente ou como parte de uma pesquisa descritiva ou experimental. Em ambos casos, busca-se conhecer e analisar as contribuições culturais e científicas do passado sobre determinado assunto, tema ou problema.

Após adquirir informações bibliográficas, será apresentado levantamento de dados a partir da pesquisa qualitativa para entender melhor a percepção dos pais, mães e outros parentes em relação à influência existente, ou seja, pesquisa quantitativa através de um formulário.

Um formulário é uma lista informal, destinado a coleta de dados resultante de observações ou interrogações, e seu preenchimento é feito pelo próprio investigador. Entre as vantagens que os formulários apresentam, podemos destacar a assistência direta do investigador, a garantia da uniformidade na interpretação dos dados e dos critérios pelos quais são fornecidos. Uma vez recolhido os dados, por meio de técnicas de observação controlada, serão apresentados gráficos dos resultados. A pesquisa descritiva, que é o foco desta pesquisa, busca observar, registrar, analisar e correlacionar fatos e variáveis sem manipulá-los. A pesquisa descritiva devolve-se, principalmente, nas ciências humanas e sociais, abordando dados e problemas que merecem ser estudados.

Ao final será apresentado um estudo de caso, que tem por objetivo mostrar uma influência real das mídias em crianças e adolescentes.

\section{SEGMENTO INFANTIL NO MERCADO}

Riccher (1991) afirma a segmentação como uma questão estratégica, onde a empresa, de uma forma consciente, estuda as características do mercado e escolhe atender um segmento específico, com a intenção de ter resultados melhores ao direcionar seus recursos disponíveis para consumidores específicos. Essa segmentação possibilita o desenvolvimento de estratégias mais focadas no segmento selecionado, o que gera lucros superiores em comparação as estratégias que abrangem mercados em massa. Brandt

O segmento infantil é composto por crianças entre idades de zero a doze anos, segundo um estudo realizado pela agência de inteligência Euromonitor, em seis anos o volume anual em vendas no segmento infantil teve um crescimento de $45,6 \%$, indo de $\mathrm{R} \$ 2,7$ bilhões para $\mathrm{R} \$ 3,9$ bilhões.

Segundo McNeal (1992), a criança pode assumir diversos papéis como consumidora: mercado primário (quando é a criança o consumidor), mercado influenciador (quando a criança influencia na hora da compra) e mercado futuro (a criança irá constituir um mercado potencial). 
O mercado infantil possui um potencial significativo e que merece atenção. A criança passa por várias mudanças entre seu crescimento e a entrada na adolescência, essa mudanças faz que elas constituam um mercado cheio de singularidades.

Mas nem sempre a criança teve um papel significativo assim no mercado, segundo McNeal (1992), somente na década de 80 a criança passa a ser um fenômeno significativo. Essa mudança começou a se firmar após o final da Segunda Guerra Mundial, através do fenômeno Baby Boom, que se refere ao crescimento da taxa da natalidade nos Estado Unidos. Através dos dados expressados por McNeal (1992), o número de crianças aumentou de 10 para 15 milhões entre 1946 e 1951. Tal fato trouxe a importância necessária para que esse segmento fosse considerado cada vez mais atrativo. 0 pós-guerra trouxe consigo a percepção de que a vida deveria ser vivida a curto prazo, com gratificações imediatas. Tal percepção foi rapidamente espalhada pela América.

A democratização da televisão na década de 50, permitiu às empresas terem um canal para acessar e se comunicar com o segmento crescente de crianças, o que originou grande apelo de propagandas direcionada a elas.

Segundo Roberts et al., (2005) dentre os diversos tipos de mídia presente no cotidiano infantil, a que mais destaca-se é a televisão, com ou sem a presença de canais pagos, como um dos meios que mais permite a comunicação entre as empresas e as crianças. É por meio da televisão e dos diferentes tipos de canais de comunicação, que as empresas conseguem transmitir suas mensagens, utilizando tanto propagandas, quanto inserções comerciais e colocação de produtos em séries, filmes e YouTube.

Em relação ao grande impacto das propagandas sobre as crianças, é questionado a grande vulnerabilidade desse público, tal vulnerabilidade ocorre pela abertura que a criança dá as informações expostas em comerciais sofisticados e alguns casos enganadores. Antes de possuir a capacidade de entender um comercial, é necessário que a criança saiba separar a programação normal da televisão (MOSES e BALDWIN, 2005).

\section{PESQUISA QUANTITATIVA}

\subsection{RESULTADOS DA PESQUISA APLICADA E DISCUSSÕES}

População é o conjunto formado por indivíduos ou objetos que têm pelo menos uma característica comum e observável (Morettin, 2010). Amostra é um subconjunto de uma população, sendo representado por $\mathbf{n}$. No presente estudo, a amostra definida é $\mathbf{n}=\mathbf{6 2}$.

A pesquisa feita foi um formulário online respondido por pessoas com diversos graus de parentesco com as crianças. 0 sexo das crianças em estudo estão divididos como mostra o gráfico 1 e a faixa etária pode ser visualizada no gráfico 2: 
Gráfico 1: Sexo das crianças em estudo no questionário aplicado Gráfico de respostas do Formulários Google. Título da pergunta: Sexo da criança. Número de respostas: 62 respostas.

Sexo da criança

62 respostas

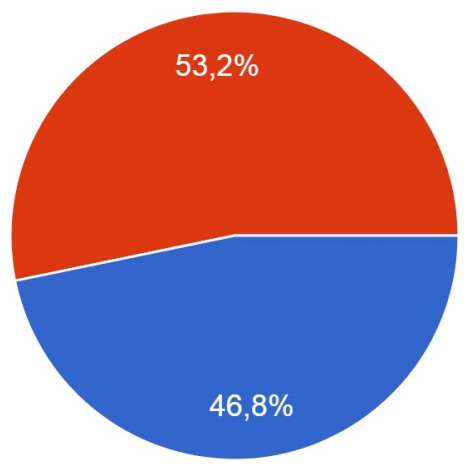

Masculino

Feminino

Fonte: Formulários Google. https://docs.google.com/forms/d/1UVUe-

P8j8plt3VNxydrJVLgDE_gxaX8inoMsgdbqqgM/edit?ts=5bedc593\#responses. Acesso em 15 de nov. de 2018.

Conforme se evidencia no gráfico 1 , as crianças possuem um pouco mais de representação no público feminino, o que auxilia nas primeiras compreensões acerca do formato e das condições dessa pesquisa.

Gráfico 2: Faixa etária das crianças em estudo no formulário Gráfico de respostas do Formulários Google. Título da pergunta: Idade. Número de respostas: 62 respostas.

\section{Idade}

62 respostas

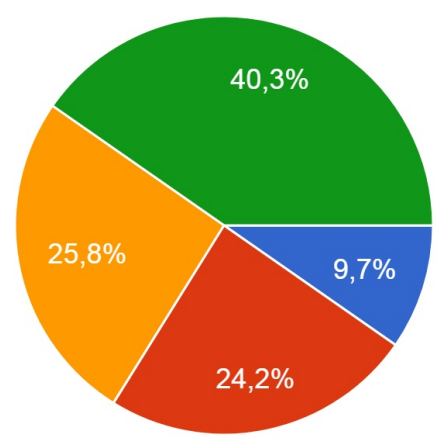

Fonte: Formulários Google. https://docs.google.com/forms/d/1UVUe-

P8j8plt3VNxydrJVLgDE_gxaX8inoMsgdbqqgM/edit?ts=5bedc593\#responses. Acesso em 15 de nov. de 2018.

O gráfico acima aponta para a idade das crianças, considerando em sua maioria crianças entre oito e doze anos de idade, esse número é significativo, visto que, crianças com essa faixa etária possuem senso crítico mais acurado e maior autonomia em suas decisões em relação aos mais novos. 
Existe um equilíbrio em relação ao percentual das crianças entre seis e oito anos e as crianças entre três e cinco anos, sendo que, as crianças com até dois anos foram consideradas minorias.

Nesse contexto, segundo as pessoas entrevistadas, 88,7\% percebe a influência de programas e propagandas infantis na vida das crianças e adolescentes. Das respostas obtidas, apenas 6 disseram não perceber a influência de propagandas e programas infantis no momento de compra versus 56 respostas positivas variando o setor de influência (roupas, calçados, alimentos, etc). A maior influência no momento de compra para as crianças do estudo são os personagens, como heróis e desenhos infantis. Roupas, alimentos, sapatos e acessórios são escolhidos de acordo com o personagem de maior interesse da criança.

Fato que reforça a hipótese apresentada de que os meios de comunicação em massa interferem no contexto do comportamento de consumo das famílias, sobretudo, considerando o público infantil como target.

$56,5 \%$ dos indivíduos disseram, ainda, que as crianças aceitam pacificamente quando é dito não no momento de compra frente $43,5 \%$ das crianças não terem boas reações às respostas negativas. Ou seja, com as reações negativas os pais se veem numa berlinda, pois, no primeiro momento existe o sentimento de ofertar o melhor aos seus filhos, mesmo que, não necessariamente seja o melhor a se fazer no contexto da educação para o consumo e, num segundo momento, fica o sentimento de recompensa oriundo de sua ausência cotidiana, visto que, em sua maioria, os pais se ausenta por conta de suas carreiras e da necessidade de adquirir recursos financeiros para o sustentáculo da base familiar.

O gráfico 3 mostra o tempo de exposição das crianças à televisão:

Gráfico de respostas do Formulários Google. Título da pergunta: Quantas horas por dia a criança passa assistindo TV?. Número de respostas: 0 / 62 respostas corretas.

Quantas horas por dia a criança passa assistindo TV?

$0 / 62$ respostas corretas

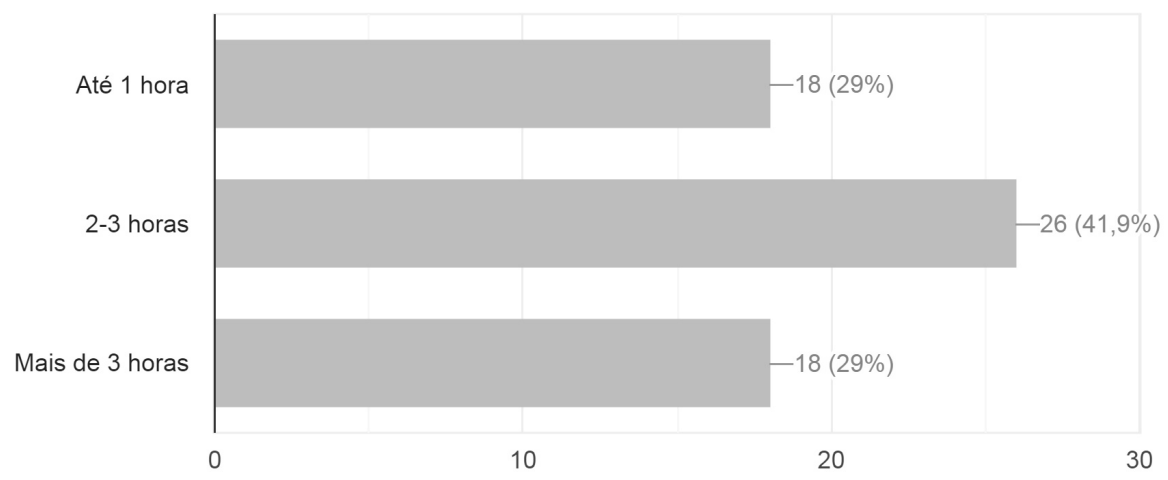

Fonte: Formulários Google. https://docs.google.com/forms/d/1UVUe-

P8j8plt3VNxydrJVLgDE_gxaX8inoMsgdbqqgM/edit?ts=5bedc593\#responses. Acesso em 15 de nov. de 2018.

Conforme se evidencia o gráfico acima, o tempo que as crianças ficam na televisão são suficientes para que as mesmas sejam influenciadas pela cultura de massa por ela explícita.

Nesse período, ficam expostas aos apelos da publicidade e da propaganda, fazendo com 
que seus pais se veja na obrigação de ofertar a elas bens e serviços de consumo que lhe são apresentados como soluções para os padrões de vida na atualidade. Por vezes, os pais, que também são influenciados pelos hábitos de consumo oriundos do capitalismo, se veem na obrigação de retribuir seus filhos por sua ausência, presenteando-os com todo o tipo de presentes que virem.

\section{CONCLUSÃO}

Ao longo da história é evidenciado que a cultura, propósitos, indagações e costumes interagem entre si colaborando para formação da comunidade, essas associações e conexões sofrem avanços constantes, a tecnologia tem sido agente promotor da globalização, conceitos universais são cada vez mais introduzidos nas comunidades, e no circulo familiar, não obstante as crianças são impactadas por esse meio e essa interação com o mundo desde o seu nascimento. Para a criança essas informações as quais são expostas fazem parte da evolução de sua vida, assim a absorção é espontânea, sem sofrimentos elas apenas incorrem, entretanto a falta de observação e controle por parte dos adultos e responsáveis permite que essas influências sejam inseridas na rotina da criança e respectivamente impactem sua formação. Logo é possível concluir que os impactos são promovidos em cadeia: os pais foram impactados e respectivamente seus filhos. Dessa forma é importante levantar a influência midiática no desenvolvimento psicológico de crianças e adolescentes. Todavia ao longo da história tradições, crenças ou valores políticos e culturais foram e são questionados, tanto quanto levantar pauta para discussão que objetiva trazer uma visão alternativa para os conceitos sociológicos vigentes na humanidade e sobre o qual repousam elementos construtivos visando a constante evolução, busca-se nesse artigo contribuir para a base educacional da criança e sua proteção frente ao mundo.

No artigo 227 da Constituição Federal são estabelecidas medidas concretas para a garantia dos direitos das crianças e adolescentes. Responsabiliza nominalmente a família, a comunidade, a sociedade e adolescentes e o Estado pelo bem-estar e saudável desenvolvimento da infância e juventude. Frente aos resultados expostos pela pesquisa quantitativa identificamos que há percepção por partes dos agentes de educação neste caso pais e escola, sobre as influências do marketing nas crianças. Direcionando apelos de vendas às emoções infantis a publicidade executa negativamente seu papel na formação das crianças. Dentre as inúmeras consequências focamos no consumismo exacerbado e inconsciente, as consequências inferem em longo prazo, formando futuros adultos consumistas. Este artigo contribui para o fomento em educação e proteção à criança frente ao consumismo excessivo que é alimentado diariamente pelos canais de comunicação atingindo a criança em fase de vulnerabilidade e desenvolvimento. Sendo responsabilidade pela educação das crianças um dever de todos.

A publicidade dirigida à criança precisa ser mais fiscalizada, portanto a regulamentação e normas mais rígidas precisam ser implantadas, pois além de impactar negativamente proporcionado aumento do consumismo não se é possível mensurar as futuras consequências nos indivíduos e sociedade. Numa sociedade capitalista onde o acumulo de riquezas é valorizado e o bem estar da sociedade é posto de forma secundária não obstante seus indivíduos sofrerão desajustes sendo assim a 
ação racional com relação ao que se projetado nos meios de comunicação voltados para as crianças e adolescentes visando proteger de forma eficiente é necessária.

Assim, essa pesquisa é contribuinte para que se possa a condição futura de nossa sociedade, pois, é característico de uma sociedade sustentável aferir condições, sociais, ambientais e, não necessariamente apenas considerar os aspectos econômicos como fator de valor maior.

Muito se fala em inovação, ruptura intelectual de conhecimento, criatividade, mas, enquanto as crianças, futuros cidadãos, forem conduzidos como marionetes pelos detentores de poder econômico-financeiros, irá prevalecer a máxima da obediência! Fato que não dialoga com os princípios expostos no início desse parágrafo como habilidades e competências necessárias ao mercado de trabalho nos dias atuais.

Ficam indagações:

Como serão as sociedades futuras?

Como o marketing e a mídia, por meio de suas manifestações em massa, irão interferir nessa formação?

E com o novo contexto social mercadológico? Com todos esses canais de comunicação oriundos das mídias digitais, como as crianças serão afetas por essas mídias?

Quais são as influências mercadológicas para essa geração nativa digita?

Quais são as interferências dos jogos eletrônicos em relação as crianças?

Questões como essas, dentre outras, podem fortalecer as relações de pesquisa nessa temática e ficam nessa artigo como propostas para pesquisas futuras, visto que, pensar a cidade futura se faz tão importante como necessário se objetivarmos uma sociedade mais justa e igualitária.

\section{REFERÊNCIAS}

CERVO, Amado Luiz. BERVIAN, Pedro Alcino. SILVA, Roberto. Metodologia Científica. $6^{\circ}$ ed. São Paulo: Pearson Education do Brasil, 2007.

KOTLER, Philip, KELLER Kevin Lane. Administração de Marketing. $14^{\circ}$ ed. São Paulo: Pearson Education do Brasil, 2013.

KOTLER, Philip, KELLER Kevin Lane. Marketing essencial: conceitos, estratégias e Casos. $5^{\circ}$ ed. São Paulo: Pearson Education do Brasil, 2013.

PALANGANA, Isilda Campaner. Desenvolvimento e aprendizagem em Piaget e Vigotski: a relevância do social. 6ํe. São Paulo, Summus, 2015.

KOTLER, Philip, KELLER Kevin Lane. Marketing essencial: conceitos, estratégias e casos. 5ํe ed. São Paulo: Pearson Education do Brasil, 2013.

PIAGET, Jean. Epistemologia genética. $2^{\circ}$ ed. São Paulo: Marins Fontes, 2002.

SILVA, Paulo Sérgio Modesto. $O$ desenvolvimento da adolescência na teoria de Jean Piaget. Disponível em: https://www.psicologia.pt/artigos/textos/TL0250.pdf. Acesso em: 10 de Novembro de 2018.

SILVA, Ana Maria Dias da. A criança e o marketing: informações fundamentais para proteger as crianças dos apelos do marketing infantil. São Paulo: Summus, 2012 p. 37.

SPC. Consumo Infantil. Disponível em:

htpps://www.spcbrasil.org.br/uploads/st_imprensa/analise_consumo_infantil_setembro_20151.pdf> Acesso em: 07 de Set. de 2018.

REIS, Ana Carla Fonseca. Marketing cultural e financiamento da cultura: teoria e prática em um estudo internacional comparado.

MORETTIN, Luiz Gonzaga. Estatística básica: probabilidade e inferência, volume único. São Paulo: Pearson Prentice Hall, 2010. 